\title{
A formação teórico-crítica do docente: a pesquisa-ação, uma experiência no México ${ }^{1}$
}

\author{
María Noemí Alfaro Mejía \\ Marisela Colín Rodea \\ Helena Maria da Silva Gomes Castro \\ Leonardo Herrera González \\ Centro de Ensino de Línguas Estrangeiras \\ Universidad Nacional Autónoma de México - CELE - UNAM
}

\begin{abstract}
O propósito deste trabalho é abordar aspectos relacionados com a formação teórica e crítica do professor de línguas, vinculados com o exercício da reflexão do docente sobre seu desenvolvimento na aula, a procura de informação e o trabalho colaborativo entre pesquisadores e professores. Para conseguir o nosso objetivo, delineamos, em primeiro lugar, o perfil do professor de línguas estrangeiras (PLE), a partir de representações existentes entre docentes de línguas estrangeiras de um curso de formação docente no Centro de Ensino de Línguas Estrangeiras na Universidad Nacional Autónoma de México (CELE-UNAM). Para efeitos práticos, faremos referência, principalmente, ao docente da educação superior, mesmo que grande parte do aqui exposto atinge outros setores educativos. Em segundo lugar, abordamos a forma em que a noção de formação de professores foi construída no México, partindo das condições sociais em que arrancaram
\end{abstract}

\footnotetext{
${ }^{1}$ Este artigo constitui o primeiro capítulo do livro La investigación-acción y la formación teórico-crítica del docente - atualmente no prelo -, cujo propósito é abordar e discutir, sob a orientação metodológica da pesquisa ação, a questão da formação de especialistas em lingüística aplicada ao ensino de línguas estrangeiras: a formação do professor, do formador de professores e pesquisadores aplicados ao estudo do ensino de línguas.

Diversas razões fundamentam esta proposta, entre as que podemos destacar, por uma parte, a própria problemática apresentada pelos programas de formação e atualização de professores e pesquisadores no âmbito de ensino de línguas estrangeiras. Por outra parte, a possibilidade de resgatar as experiências e reflexões surgidas no desenvolvimento do projeto Interacción en el Salón de Clase de Portugués como Lengua Extranjera: Investigación-acción (PIA-PLE). O projeto foi levado a cabo no Departamento de Lingüística Aplicada do Centro de Enseñanza de Lenguas Extranjeras da UNAM, de fevereiro de 1994 a novembro de 1998.
} 


\begin{abstract}
determinados programas de planejamento educacional, os quais procuravam favorecer a atualização acadêmica no país. Já na parte final do artigo, contextualizamos a nossa experiência como participantes no projeto Interação na sala de aula de Português como Lingua Estrangeira, PesquisaAção (PIA-PLE), levado a cabo na mesma universidade.

The aim of this article is to explore issues related to the theoretical and critical formation of foreign language teachers, linked with the teacher's reflection about his work in class and the search of information, as well as the colaborative work among teachers and researchers. First, we delineate a profile of a foreign language teacher in the Centro de Enseñanza de Lenguas Extranjeras at the Universidad Nacional Autónoma de México (CELE-UNAM). Then, we study the way the notion of teacher's training was built in Mexico, in the social context where the educational programs in our country began, aiming at encouraging academic actualization. Finally, we talk briefly about our experience in the project "Interaction in the classroom of Portuguese as a Foreign Language, Action Research (PIA-PLE)", developed in the same University.
\end{abstract}

\title{
O professor de línguas
}

Consideramos que uma maneira de delinear a figura do professor de línguas estrangeiras consiste em defini-la a partir de sua própria prática profissional; é nela que se constrói socialmente e, de maneira mais específica, na relação que estabelece de maneira institucional com seus alunos. Outro aspecto importante dessa definição, como já dissemos, encontra-se nas metodologias de ensino e as teorias que as sustentam.

Assim, quando indagamos entre os docentes em prática sobre uma definição do docente de línguas, encontramos dados, ora contrastantes, ora coincidentes, que organizamos no QUADRO 1. Trata-se de informação que pode ser apresentada em dois eixos: um eixo vertical, integrado por 4 categorias: o professor de línguas, a docência, a experiência e a formação de professores; e, em correlação, o eixo horizontal, que exprime cinco representações atuais do professor de línguas: a de transmissor de informação, a de ponte entre a LE e o aluno, a de professor por vocação, a de facilitador e a de pesquisador/educador.

Cada um dos elementos no QUADRO refere-se a uma maior ou menor experiência do professor. No caso dos nossos informantes, tratavase de professores que iniciavam um processo formativo, portanto os seus dados exprimem-se como indícios, expectativas, crenças e afirmações dos aspectos que definem um docente de línguas estrangeiras e a sua atividade profissional. 
QUADRO 1

Noções básicas em volta da figura do professor e a formação docente

\begin{tabular}{|c|c|c|c|c|c|}
\hline $\begin{array}{l}\text { Professor } \\
\text { de línguas }\end{array}$ & $\begin{array}{l}\text { Transmissor de } \\
\text { conhecimentos }\end{array}$ & $\begin{array}{l}\text { Ponte entre } \\
\text { culturas }\end{array}$ & $\begin{array}{l}\text { Professor por } \\
\text { vocação }\end{array}$ & Facilitador & $\begin{array}{l}\text { Pesquisador- } \\
\text { educador }\end{array}$ \\
\hline Docência & $\begin{array}{l}\text { Compartilhar } \\
\text { conhecimentos, } \\
\text { aprender }\end{array}$ & $\begin{array}{l}\text { Responsabi- } \\
\text { lidade } \\
\text { paciência } \\
\text { dedicação }\end{array}$ & $\begin{array}{l}\text { Estabelecer } \\
\text { conexão com a } \\
\text { metodologia e } \\
\text { com o professor }\end{array}$ & $\begin{array}{l}\text { Formar alunos } \\
\text { para adquirir } \\
\text { conhecimentos } \\
\text { por eles } \\
\text { mesmos / } \\
\text { despertar } \\
\text { interesse e } \\
\text { ensinar a } \\
\text { pensar em LE }\end{array}$ & $\begin{array}{l}\text { Usar metodologias, } \\
\text { técnicas e teorias } \\
\text { para tornar mais } \\
\text { autêntica uma } \\
\text { uma língua / } \\
\text { resolver problemas }\end{array}$ \\
\hline Experiência & $\begin{array}{l}\text { Assistir a } \\
\text { congressos para } \\
\text { aprender técnicas } \\
\text { e por motivação }\end{array}$ & $\begin{array}{l}\text { Experiência } \\
\text { profissional } \\
\text { pessoal }\end{array}$ & $\begin{array}{l}\text { Aprendizagem } \\
\text { da LE: } \\
\text { "Viver na LE" }\end{array}$ & $\begin{array}{l}\text { Conhecimentos } \\
\text { e experiências }\end{array}$ & $\begin{array}{l}\text { Reciprocidade de } \\
\text { conhecimentos } \\
\text { e atitudes }\end{array}$ \\
\hline $\begin{array}{l}\text { Formação } \\
\text { de } \\
\text { professores }\end{array}$ & $\begin{array}{l}\text { Estudar mais } \\
\text { formalmente } \\
\text { e aportar }\end{array}$ & $\begin{array}{l}\text { Desenvolver } \\
\text { habilidades } \\
\text { de ensino e de } \\
\text { compreensão } \\
\text { dos processos }\end{array}$ & $\begin{array}{l}\text { Forma de } \\
\text { aprender/ } \\
\text { conhecimentos } \\
\text { e técnicas para } \\
\text { facilitar o } \\
\text { processo ensino- } \\
\text { aprendizagem }\end{array}$ & $\begin{array}{l}\text { Adquirir uma } \\
\text { competência } \\
\text { lingüística, } \\
\text { comunicativa } \\
\text { e social / } \\
\text { Adquirir } \\
\text { habilidades e } \\
\text { técnicas básicas }\end{array}$ & $\begin{array}{l}\text { Ensinar a utilizar } \\
\text { teorias, } \\
\text { metodologias / } \\
\text { Aprender opções } \\
\text { para ensinar } \\
\text { melhor. }\end{array}$ \\
\hline
\end{tabular}

Nota: Dados colhidos em depoimentos de alunos-professores do CELE-UNAM, 2004

Segundo esses dados, a figura do professor é concebida atualmente em volta de três idéias: de responsabilidade (sinônimo de obrigação por adquirir uma formação profissional); de mediação (entendida como uma ponte física e intelectual que lida com vários tipos de conhecimentos lingüístico, comunicativo e cultural); e, finalmente, a de reflexão crítica, na qual o professor é concebido como membro de uma comunidade específica, sensível às necessidades de dois contextos: o da sala de aula e o social.

É importante dizer que, mesmo que identifiquemos nos nossos informantes um contínuo existente nas representações em volta da figura do professor de línguas, ele passa por diferentes níveis de experiência, os quais são percebidos em alguns docentes (D1) como conclusões bem claras sobre sua profissão, como podemos apreciar na seguinte reflexão:

La tarea de transmitir el conocimiento no es fácil, en una lengua extranjera lo es menos. El profesor de lengua extranjera debe estar consciente del medio que rodea no sólo a un alumno sino a todos y cada uno de ellos. El 
proceso de enseñanza-aprendizaje entonces estará condicionado por todos estos factores que dependen del medio que rodea a sus alumnos. La formación del profesor es parte de su compromiso con los alumnos, se debe saber lo que se quiere enseñar y si el conocimiento es mayor un problema está resuelto. Sin embargo, creo también que la afectividad es algo que no se debe pasar por alto, creo que la razón, el buen trato y el respeto facilitan el aprendizaje del alumno, a veces incluso, la paciencia, comprensión e interés pueden más que cualquier regla, fórmula o técnica. Quizá el afecto pueda ser una técnica, no la mejor para aprender en todos los casos pero sí la mejor para abrir cualquier puerta (D1). ${ }^{2}$

Em outros docentes (D2, D3, D4), essa figura mantém-se sob a idéia de que os cursos de formação permitirão adquirir habilidades e técnicas para conseguir um processo de ensino-aprendizagem eficiente, segundo podemos ler nos seguintes enunciados:

[f]ormación de profesores es el curso que nos enseña las diferentes tácticas, metodologías, criterios, etc.... que son necesarios para la enseñanza eficiente de un idioma (D2); ${ }^{3}$

[e]l profesor de lenguas extranjeras deberá poner particular interés en el proceso de enseñanza-aprendizaje, para permitir el desarrollo en los alumnos de las habilidades o destrezas, según el enfoque comunicativo que se esté aprendiendo en el curso de formación de profesores (D3); ${ }^{4}$

\footnotetext{
${ }^{2}$ A tarefa de transmitir o conhecimento não é fácil, muito menos em uma língua estrangeira. O professor de língua estrangeira deve estar consciente do meio que rodeia não só um aluno mas todos e cada um deles. O processo de ensino-aprendizagem estará, então, condicionado por todos esses fatores que dependem do meio que rodeia seus alunos. A formação do professor faz parte do seu compromisso com os alunos, ele deve saber o que quer ensinar, e, se o conhecimento for maior, um problema estará resolvido. Contudo, acho também que a afetividade é algo que não deve ser ignorado, acho que a razão, o bom acolhimento e o respeito facilitam a aprendizagem do aluno, às vezes até a paciência, compreensão e interesse podem mais que qualquer regra, fórmula ou técnica. $\mathrm{O}$ afeto talvez possa ser una técnica, não a melhor para aprender em todos os casos, mas a melhor para abrir qualquer porta (tradução nossa).

${ }^{3}$ Formação de professores é o curso que nos ensina as diferentes táticas, metodologias, critérios, etc.... necessários para o ensino eficiente de um idioma (tradução nossa).

${ }^{4} \mathrm{O}$ professor de línguas estrangeiras deverá prestar uma particular atenção ao processo de ensino-aprendizagem, para permitir o desenvolvimento, nos alunos, das habilidades ou destrezas, segundo a abordagem comunicativa que se esteja aprendendo no curso de formação de professores (tradução nossa).
} 
[v]oy a narrar mi experiencia en el proceso de enseñanza de una lengua extranjera. Me convertí en profesora de inglés a los 18 años sin tener alguna preparación formativa, sino simplemente por ser el inglés mi lengua materna. A través de los años participé en cursos de formación y adquirí experiencia en el salón de clase. Digamos que fue un proceso muy difícil y sufrí mucho tratando de preparar clases y buscar información por mi cuenta. No lo recomiendo. Siento que un maestro debe de tener una formación adecuada, no sólo saber hablar un idioma sino conocimientos lingüísticos y de metodología, etc. El proceso de enseñanza debe ser efectivo para los que desean aprender (D4). ${ }^{5}$

Perante essas idéias, devemos pensar que a imagem do docente na mente desses informantes oferece-nos elementos suficientes para conformar um perfil aproximativo do profissional.

A partir das mudanças metodológicas instrumentadas com o advento da Abordagem Comunicativa, podemos afirmar que um professor de línguas: inicia, dirige e avalia ações discursivas; oferece mostras modelo da língua que ensina; repete expressões manifestas dessa mesma língua; seleciona documentos que usará, modificados, como auxiliares didáticos, a partir de critérios de conteúdo lingüístico ou referencial; aplica avaliações formais dando maior atenção, freqüentemente, ao uso do código ou língua que ensina; oferece informação específica sobre a realidade cultural da língua alvo ou faz considerações sobre ela, posicionando-se como sujeito diante dela; estabelece as regras do jogo sobre como irão trabalhar e toma decisões como cabeça de uma comunidade de fala (SEEDHOUSE, 1994); determina os objetivos que essa comunidade conseguirá no final do curso, entre outras tantas ações específicas.

É precisamente esta multiplicidade de funções que nos leva a fazer diversas perguntas para as quais se espera uma resposta: O que realmente faz um verdadeiro professor de linguas estrangeiras? O que há nesse caminho tão complexo do processo de ensino-aprendizagem? Por que tantas pessoas querem aulas de inglês mas não querem trabalhar, mesmo

\footnotetext{
${ }^{5}$ Vou contar a minha experiência no processo de ensino de uma língua estrangeira. Virei professora de inglês aos 18 anos sem nenhum preparo formativo, mas apenas por ser o inglês a minha língua materna. Através dos anos fiz cursos de formação e ganhei experiência na sala de aula. Digamos que foi um processo muito difícil e sofrí muito tentando preparar aulas e procurando informação pela minha conta. Eu não recomendo. Sinto que um professor deve ter uma formação adequada, não só saber falar uma língua mas ter conhecimentos lingüísticos e de metodologia, etc. O processo de ensino deve ser efetivo para os que querem aprender (tradução nossa).
} 
para aprender essa lingua? Por que é que essa matéria é a sexta com o maior número de repetência? E você, onde aprendeu a ensinar?

\section{O que é a formação de professores?}

Daí a importância de refletir sobre a noção de formação de professores, visto que ela foi construída em diferentes momentos, de maneira muito próxima a teorias lingüísticas específicas, permitindo assim aplicações didáticas derivadas das mesmas concepções.

Por exemplo, podemos citar o caso das escolas de tradutores na antigüidade do mundo ocidental. Durante a Idade Média essa atividade e o seu ensino eram realizados nos mosteiros, onde os amanuenses transcreviam - geralmente do grego clássico para o latim -, tratados e obras de história, teologia, literatura, filosofia e botânica, entre outras matérias. O principal propósito no uso dessas línguas era resgatar informação preciosa, cuja divulgação e aplicação foram determinantes no passado clássico da humanidade. No entanto, a falarmos desses tempos, não podemos afirmar que o ensino de línguas tivesse então a mesma difusão que tem atualmente.

Entre os séculos XIII e XV - e de maneira muito reduzida, visto que a educação elementar ainda não era algo muito comum -, nas cortes européias existiam os "mestres de línguas", cuja função era ensinar as línguas maternas de maneira muito descritiva e tendo, quase sempre, como base o latim. A idéia prevalescente era que a formação do pensamento era favorecida com o estudo sistematizado dessa língua. Nessas circunstâncias procurava-se também a aprendizagem de uma língua estrangeira, geralmente as línguas de prestígio nas cortes ou para fins de uso no comércio. Da mesma maneira, e durante muitos anos, as pessoas que optavam pela docência de línguas contavam apenas com o método direto de tradução, e só em situações excepcionais faziam um estudo de reflexão explícita apoiado nas gramáticas clássicas. Nesses casos, tampouco, poderíamos falar de uma sistematização do ensino de línguas estrangeiras, pois grande parte desse trabalho estava "baseado quase exclusivamente na intuição e no sentido comum" (RICHARDS; NUNAN, 1990, p. 3).

No século XX, época de grandes avanços no que diz respeito a posturas e argumentos em volta da natureza da linguagem e a sua aprendizagem pelo homem, retoma-se também a discussão e estudo dos papéis conferidos aos professores nas diferentes metodologias de línguas estrangeiras. No QUADRO 2, mostramos os diferentes papéis atribuídos 
ao professor de línguas em diferentes épocas, e sob a perspectiva de diferentes teorias de aprendizagem e modelos lingüísticos diversos. A informação no mesmo quadro nos permite apreciar que a figura do professor é construída em função do tipo de ações que metodologicamente lhe foram atribuídas.

Com a chegada do estruturalismo, cujas bases conceituais serviram para refletir sobre a natureza da linguagem, pensaria-se também na existência de uma homogeneidade lingüística, análoga às línguas indo-européias. Mas em breve admitiria-se que não é possível fazer tal generalização, ${ }^{6}$ abrindo assim as discussões que décadas posteriores permitiriam os argumentos da Gramática Generativa.

QUADRO 2

Os modelos lingüísticos e a noção de professor

\begin{tabular}{|c|c|c|c|c|}
\hline $\begin{array}{l}\text { Modelos } \\
\text { lingüísticos }\end{array}$ & Finalidade & $\begin{array}{c}\text { Aplicação } \\
\text { Didática }\end{array}$ & Aluno & Professor \\
\hline $\begin{array}{l}\text { Gramática } \\
\text { tradicional } \\
\text { Lingüística } \\
\text { estrutural }\end{array}$ & $\begin{array}{l}\text { Estabelecer taxo- } \\
\text { nomias. Identifi- } \\
\text { car e classificar } \\
\text { unidades do cor- } \\
\text { pus em paradig- } \\
\text { mas e níveis. }\end{array}$ & $\begin{array}{l}\text { Gramática normativa (L1) } \\
\text { Gramática tradução (L2) } \\
\text { Método áudio-lingual (L2) } \\
\text { Análise contrastiva (L2) }\end{array}$ & $\begin{array}{l}\text { Elemento passivo, } \\
\text { paciente } \\
\text { Participante ativo }\end{array}$ & $\begin{array}{l}\text { Ensina a norma } \\
\text { escrita } \\
\text { Maneja de ma- } \\
\text { neira superficial } \\
\text { ou inadequada } \\
\text { a teoria }\end{array}$ \\
\hline $\begin{array}{l}\text { Gramática } \\
\text { gerativa }\end{array}$ & $\begin{array}{l}\text { Analisar os } \\
\text { componentes da } \\
\text { gramática e for- } \\
\text { mular princípios }\end{array}$ & $\begin{array}{l}\text { Abordagem cognitiva (L2) } \\
\text { Análise de erros e } \\
\text { inter-linguagem (L2) }\end{array}$ & Participante ativo & $\begin{array}{l}\text { Maneja de ma- } \\
\text { neira superficial } \\
\text { ou inadequada } \\
\text { a teoria }\end{array}$ \\
\hline $\begin{array}{l}\text { Lingüística } \\
\text { textual }\end{array}$ & $\begin{array}{l}\text { Analisar a produ- } \\
\text { ção dos falantes } \\
\text { de maneira } \\
\text { contextualizada }\end{array}$ & $\begin{array}{l}\text { Abordagem comunicativa: } \\
\text { Método nocional - } \\
\text { funcional (L2) } \\
\text { Tipologias textuais (L1,L2) }\end{array}$ & $\begin{array}{l}\text { Elemento intera- } \\
\text { tivo }\end{array}$ & $\begin{array}{l}\text { Facilita, promove } \\
\text { o desenvolvi- } \\
\text { mento da compe- } \\
\text { tência comuni- } \\
\text { cativa e a com- } \\
\text { preensão de } \\
\text { leitura }\end{array}$ \\
\hline $\begin{array}{l}\text { Lingüística } \\
\text { Aplicada } \\
\text { Crítica }\end{array}$ & $\begin{array}{l}\text { Correspondência } \\
\text { entre pensamento } \\
\text { conceitual, a ex- } \\
\text { periência corpó- } \\
\text { rea e a estrutura } \\
\text { lingüística }\end{array}$ & $\begin{array}{l}\text { Abordagens inter-cultu- } \\
\text { turais. Mecanismos } \\
\text { cognitivos. Funciona- } \\
\text { lismo não formal. } \\
\text { Lingüística textual. } \\
\text { Análise do discurso. }\end{array}$ & $\begin{array}{l}\text { Constrói-se } \\
\text { socialmente em } \\
\text { diferentes } \\
\text { discursos sociais }\end{array}$ & $\begin{array}{l}\text { Trabalha impli- } \\
\text { cações sociais, } \\
\text { culturais e } \\
\text { cognitivas. }\end{array}$ \\
\hline
\end{tabular}

Nota: Baseado no trabalho de Cuenca, 1993, p. 26

${ }^{6}$ A respeito disso são importantes os estudos de gramáticos e antropólogos norteamericanos, como Boas e Sapir (Language: An Introduction to the Study of Speech, New York, 1921), interessados em observar e descrever os traços fonéticos e a sistematicidade de algumas línguas indígenas dessa região. 
Sob outros contextos, os primeiros trabalhos que procuravam a profissionalização do ensino de línguas estrangeiras foram realizados nos principais centros de estudo lingüístico da Europa e da América do Norte e tornaram interdisciplinários os aportes de psicólogos, pedagogos e lingüistas. Esses estudos e propostas destacavam mais as questões lingüísticas, isto é, grande parte da atenção de formadores e formandos era orientada ao estudo da competência lingüística, primeiro com relação ao ensino de conteúdos ( o quê) e depois ao ensino de uma metodologia ( o como). Dessa maneira, e segundo observamos na FIG. 1, a ênfase estava no estudo formal da linguagem, estudo em que os dois componentes são correlativos e determinantes um do outro: "deve-se ensinar assim porque o que interessa é preconizar a forma (lingüística)"; "consegue-se a aprendizagem adequada desse ponto lingüístico através da exposição do aluno a uma prática constante esse ponto"; "não é clara sua mensagem porque você não usa a forma certa”.

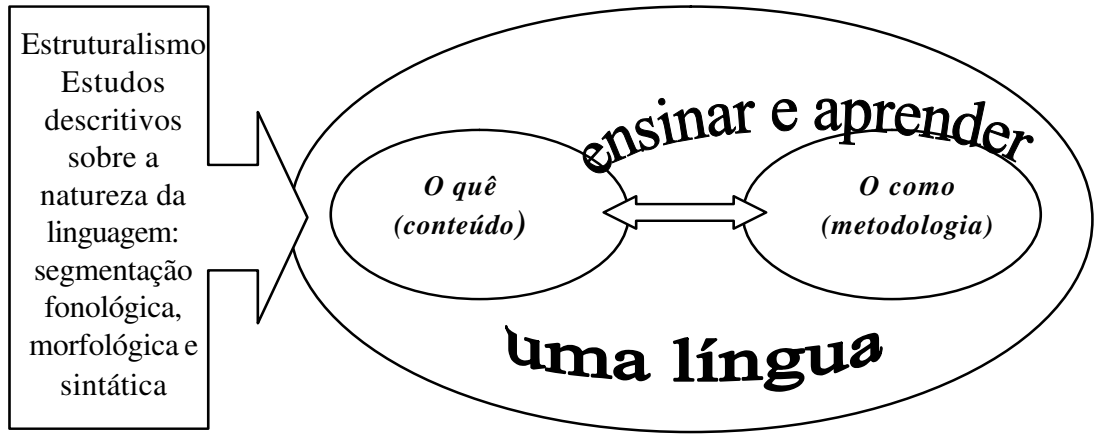

FIGURA 1 - Correlação entre conteúdos e metodologia do ensino de línguas estrangeiras segundo a proposta estruturalista. ${ }^{7}$

Nessas condições, a figura do professor e as características formais ou qualitativas do seu desempenho estavam também no centro da discussão. Privilegiava-se principalmente a visão da língua como um produto - "dominar uma língua é dominar basicamente o seu código lingüístico", conhecer sua gramática, o vocabulário, etc.-, deixando de fora outros fatores como, por

${ }^{7}$ Esta mesma díade (o quê - o como) estará na base mais afinada das propostas da Abordagem Comunicativa. ( $\mathrm{O}$ conhecimento de uma língua (código) e o conhecimento de sua aplicação (as regras de uso) (GERMAIN, 1984). 
exemplo, a capacidade cognitiva do falante e o caráter social e interativo da língua.

Essas propostas teóricas iniciais vinculavam a formação com a procura de fundamentos teóricos sobre a natureza da linguagem e, aos poucos, ganhavam espaço o estudo dos processos de aprendizagem e o uso da língua dentro e fora da sala de aula, embora isso não garantisse que os futuros professores assimilariam essa bagagem teórica e informação de maneira reflexiva.

[Os] professores são treinados no uso de técnicas, típicas de métodos específicos de ensino [...] são treinados a partir de determinados modismos sobre como ensinar línguas, quer dizer, recebem uma formação pautada por dogmas (MOITA LOPES, 1996, p. 180).

Esses "modismos", que constituem o quadro para as ações e procedimentos do docente em sua prática profissional, foram ganhando um espaço nas tradições acadêmicas ${ }^{8}$ e foram conformando o que Almeida Filho (1991) chama de cultura de ensinar (ou aprender) linguas. Quer dizer, tudo aquilo que ganha aceitação entre os docentes desse âmbito quanto à maneira em que se deve ensinar uma língua, deve ter, na aula, uma prática de exercícios estruturados, exercícios de completar, prática oral, materiais específicos, meios audiovisuais, dicionários, gramáticas, jogo de papéis, um ambiente ou atmosfera adequados, deveres de casa, exames institucionais, etc. ${ }^{9}$ E essa cultura de ensinar linguas inclui todos esses elementos que caracterizam uma aula de língua como imprescindível.

Assim, dentro da dinâmica gerada por esses elementos presentes na formação e exercício profissional do docente de línguas, podemos observar

\footnotetext{
${ }^{8}$ Essas tradições de ensino variam em cada uma das sociedades. Nos últimos tempos, constituem também uma linha de estudo da lingüística aplicada, conhecida como o estudo das representações.

${ }^{9}$ Há uma suposta necessidade de garantir a efetividade do ensino, como se o ensino de uma língua fosse algo mecanicamente operável e estivesse sujeito ao bom seguimento das pautas encomendadas nas apresentações metodológicas de todo material didático. Não ignoremos que a principal finalidade em todo material didático de grande tiragem - mormente tratando-se de alguma língua hegemônica -, é promover seu produto (o manual ou livro) e garantir-lhe um lugar na preferência dos usuários da sala de aula. São processos diferentes: o dos distribuidores do livro termina no momento em que o produto é adquirido; nessas circunstâncias, os autores dificilmente poderão fazer qualquer seguimento que dê conta de seu trabalho.
} 
também uma evolução conceitual de sua disciplina, istoé, tem-se implementado uma terminologia ou uma metalinguagem que os docentes de línguas utilizam para fazer referência a tudo relacionado com a sua prática profissional. Essa metalinguagem é adquirida, em um primeiro momento, durante a etapa formativa do docente, e posteriormente na troca de informações com outros colegas, no cotidiano, ou bem ao freqüentar espaços acadêmicos especializados: foros, encontros, congressos, etc. O uso dessa metalinguagem faz dele o membro de uma comunidade profissional. ${ }^{10}$

Uma parte significativa dos professores de línguas estrangeiras teve a oportunidade de formar-se, especificamente, nessa área da docência humanista. Em outros casos, alguns deles contam apenas com o conhecimento pessoal da língua em questão, por tratar-se da sua língua materna. Um terceiro grupo, talvez o menor, é constituído por pessoas que tiveram contato e usaram diretamente o idioma, ao viver uma temporada num país estrangeiro. Dessa maneira, a possibilidade de exercer profissionalmente o ensino dessa língua leva o professor, devido aos requerimentos institucionais, a passar por uma etapa de treinamento ou etapa formativa, de duração variável, que lhe permita certificar a sua habilitação. O cumprimento dessa exigência variará segundo as expectativas das instituições implicadas.

Ao falarmos em formação inicial ou continuada do docente de línguas, nacionais ou estrangeiras, ${ }^{11}$ referimo-nos a um âmbito de considerável magnitude e com problemas muito específicos. No caso do México, consideramos que todo processo formativo na área deve integrar-se ou descrever-se a partir de dois diferentes níveis de estudo:

1. um interno (o contexto institucional), que encontra subsídios na lingüística aplicada, a qual the dá coerência e the permite abordar o seu objeto de estudo; e

2. outro externo (o contexto histórico), de planejamento educativo, que relaciona necessariamente essa formação com um contexto político, social e tecnológico.

Podemos apreciar essa correlação na FIG. 2.

\footnotetext{
${ }^{10}$ Ao falarmos da bagagem terminológica e da sua utilização pelos profissionais docentes, referimo-nos à possibilidade de promover o conhecimento de sua matéria.

${ }^{11}$ Referimo-nos a professores de línguas estrangeiras e aos cada vez mais numerosos professores de línguas não "oficiais", como é o caso dos professores que usam uma língua indígena no território nacional.
} 


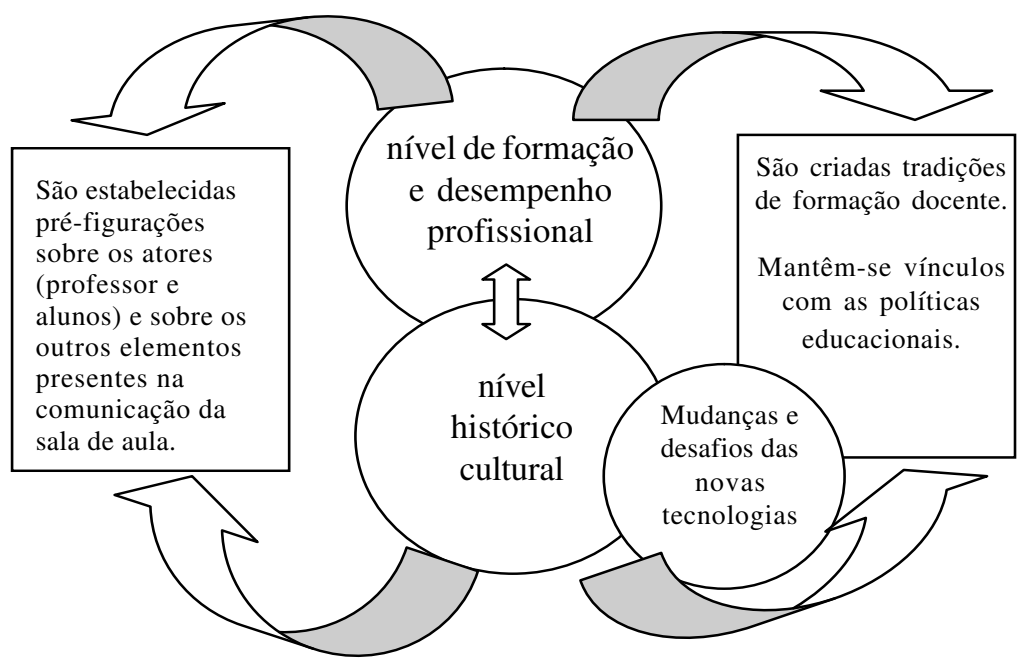

FIGURA 2 - Níveis de estudo na concepção da formação do docente de línguas no México

Observamos na proposta anterior que não é possível falar em formação de professores sem levar em conta as condições históricas que determinam que a dita formação do docente deve ser de uma ou de outra maneira: o que ele deve aprender para ser um professor de línguas; onde, como e para que se forma; sua formação corresponde ou não com a oferta de trabalho; ou que responda a uma série de questões institucionais, como quantos professores forma cada instituição, como e segundo quem.

Entendemos que essas condições sejam quase sempre delimitadas segundo os interesses pessoais ou institucionais. Nesse caso, consideremos, segundo os interesses governamentais, em prol das expectativas colocadas como objetivos a serem atingidos pelos programas oficiais, nem sempre com base em uma realidade evidente, a perspectiva externa a que já nos referimos. Por exemplo, pode-se pensar que a integração do México ao Tratado de Livre Comércio da América do Norte (NAFTA, segundo suas siglas em inglês) obriga a integrar ações para a formação urgente de professores de inglês ou de francês (para o caso do Canadá). ${ }^{12}$

\footnotetext{
${ }^{12}$ A mesma procura de trabalho e de formação por parte dos futuros professores se explica em sua necessidade de inserção em um sistema produtivo com profundas relações históricas e sociais.
} 
Considerando novamente essa correlação entre o desempenho profissional do docente e o contexto sócio-histórico, podemos afirmar que, de maneira específica no âmbito do ensino de línguas, a pesquisa educativa começou a avançar paralelamente com os processos formativos do docente por volta dos anos setenta. As iniciativas oficiais, resultantes do planejamento educacional no México, são apresentadas, quase sempre, em forma de cursos de atualização. Nesses cursos, o imperativo parece ser o oferecimento de informação nova sobre metodologia e sobre a concepção do ensino.

Iniciativas como essas justificam a aquisição de tecnologia educativa, ${ }^{13}$ uma aquisição às vezes precipitada ou desvinculada de um conhecimento das necessidades reais. No entanto, essa habilitação no manejo das técnicas mais novas não implica necessariamente um trabalho verdadeiramente produtivo ou eficaz, sustentado na reflexão da prática profissional: "instrumenta-se para não refletir" (DÍAZ BARRIGA, 1990, p.14).

O construto formação de professores é relativamente recente no âmbito nacional. Díaz Barriga (1990) reporta a década de setenta como um período especialmente rico em articulações e propostas no campo "como resultado da política de modernização educacional e da educação superior em particular". ${ }^{14}$ Essa iniciativa, relacionada com noções tecnológicas da época - e novamente na moda na década de noventa - como eficiência, produtividade e utilidade, foi integrada sob a forma de cursos de treinamento docente, através dos quais se pretende dotar os professores de informação nova no que diz respeito à metodologia e à noção de ensino.

Contudo, ainda era necessária a integração de uma área de pesquisa educativa que ajudasse no acompanhamento, reflexão e superação dos problemas que a prática docente enfrentava; algo que a habilitação emergente dificilmente satisfaria. Essa necessidade de atenção implicava também a integração de um componente teórico, a partir do qual poderia se empreender um trabalho de reflexão, reconhecimento e crítica à instrumentação das mudanças. Toda postura teórica faz referência, indefectivelmente, a uma perspectiva histórica em que se inscreve a matéria ou o fenômeno estudado, no nosso caso "a educação como prática social não neutral" (IMBERNON, 1994, p. 35). E ainda, atualmente a educação

\footnotetext{
13 "Inglês e computação", a palavra de ordem nos últimos governos neo-liberais no México.

${ }^{14}$ (Ibid., p. 7).
} 
em língua estrangeira deve se dar no envolvimento do aluno na construção de significados. Autores como Moita Lopes (2003) alertam sobre a necessidade dessa mudança:

[...] aprender língua é igual a aprender a se engajar, no próprio espaço em que se vive, nos significados que circulam naquela língua. [...] O que é central é o envolvimento no discurso e, portanto, nos significados construídos naquela língua em todas as aulas, de modo que seja possível pensar tais significados em relação ao mundo no qual se vive. Isso significa se engajar no discurso, ou seja, agir no mundo por meio dos discursos que em inglês possibilitam com base nas marcas sócio-históricas que temos como homens, mulheres, negros, brancos, homoeróticos, pobres, ricos, com terras, sem terras, etc. (MOITA LOPES, 2003, p. 45).

Dessa maneira, o ensino de línguas está intrinsecamente relacionado com aspectos sociais e políticos. O trabalho com a linguagem na aula de língua estrangeira não fica à margem dos tópicos sociais emergentes - nem sempre conflitivos, o que assusta a muitos -, como resultado da própria interação na sala de aula, levando os alunos a participar em intercâmbios que implicam, nas palavras de Moita Lopes (Op. cit.), "estar no centro de ação social".

\section{Teoria e prática}

Por outra parte, um assunto relacionado com a formação do professor, no âmbito do ensino de línguas estrangeiras, é a relação estreita entre a teoria e a prática, vínculo nem sempre tão visível para os docentes.

Partimos da pressuposição de que, quando se fala em formação, se faz referência ao domínio de um âmbito teórico multidisciplinar, de relação muito próxima entre as disciplinas que o integram: pedagogia, psicolingüística, conhecimentos lingüísticos da língua alvo, etc.

Enquanto a teoria parece estar sempre relacionada com conteúdos programáticos, a prática é considerada, convencionalmente, como a aplicação da bagagem teórica adquirida em outros momentos: o período formativo, os insumos conseguidos em foros acadêmicos - oficinas, congressos, seminários -, para depois levá-los à prática. Na FIG. 3, representa-se a maneira tradicional de entender a teoria e a prática, relacionadas respectivamente com as noções de habilitação e de aplicação. 


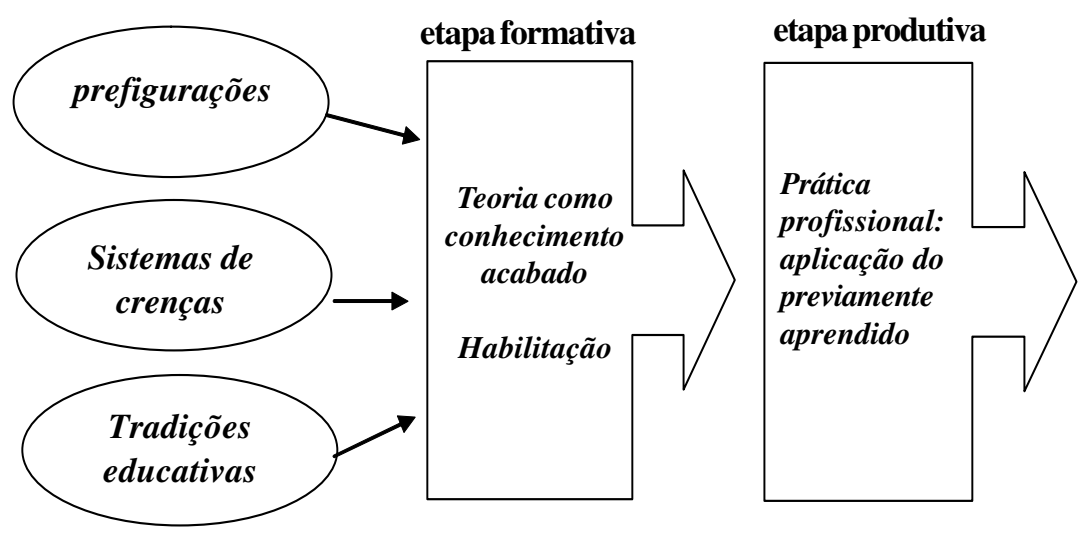

FIGURA 3 - Visão tradicional do vínculo entre teoria e prática

Esta percepção da teoria - centrada nas noções de habilitação e de aplicação - pelo docente e pelos formadores, leva-nos a procurar informação sobre aqueles elementos ou aspectos da prática cotidiana da sala aula de línguas que demandam a sua atenção como parte fundamental nas atividades de ensino para os futuros professores. Contudo, podem aparecer também alguns inconvenientes nessa seleção de elementos: uma falta de correspondência entre os conteúdos temáticos escolhidos para integrar um curso de formação com o âmbito para o exercício profissional, uma inadequada ação metodológica para levar a cabo o estudo e discussão com outros participantes, ou a falta de compreensão como resultado dessa mesma carência de réplica construtiva.

Na procura empreendida pelos formadores do professor de línguas, a principal preocupação foi, quase sempre, vincular a informação teórica com os recursos metodológicos que garantissem ao docente um desempenho bem-sucedido, o qual, acham, deve estar relacionado com o cumprimento de um programa. Através de um conjunto de pressuposições ou pensamentos - já referidos na análise dos depoimentos de professoresalunos -, começa também a articulação de visões ou o imaginário sobre o afazer profissional, sem deixar de perceber que é a teoria o elemento reitor da atuação do professor na sala de aula. Mas em muito poucos casos podemos considerar que a teoria seja vista como algo dinâmico, sujeita a julgamento à medida que se confronta com a mesma prática profissional ou quando é discutida - até informalmente, nas conversas no corredor da escola - pelos professores, como parte de uma série de atividades, institucionais ou não, que expressem suas inquietações. 
Os autores a que recorrem os formadores em busca de insumos e pressupostos refletem, quase sempre, uma visão específica da problemática abordada, mas essa visão não corresponde necessariamente com os problemas, perguntas ou aspectos que estarão na mira dos formadores, tanto no momento de optar pela informação teórica como na ação de analisar as particularidades da prática que se aplicarão os professores em formação: ensino para adultos, ensino de inglês para uma escola rural, ensino da língua com propósitos definidos, ensino para a certificação, etc. Perante essas condições, convém então nos perguntar: há um conhecimento das condições sociais ou laborais para as quais o futuro professor quer se formar; o curso conta com uma seleção adequada de conteúdos e de informação teórica?; quem faz essa seleção?; com que critérios?; além dos textos teóricos e artigos especializados, quem e como determina a maneira em que se procederá nos cursos de formação para abordar e discutir a informação?; quer dizer, teoria para que ou para onde?

Na nossa apreciação, a teoria deve corresponder ao estudo de aspectos tão diversos como os processos cognitivos dos sujeitos para adquirir a língua, os procedimentos ou ações da sala de aula, as características ou papéis dos participantes nesse âmbito, os materiais com que se trabalha, a comunicação ou como e de que se fala na sala de aula de línguas, o trabalho individual ou de grupo, entre outros.

Outro problema radica no fato de que grande parte da teoria sobre aprendizagem e lingüística aplicada é gerada e provém dos centros hegemônicos de estudo, isto é, do Norte da Europa e da América. Essa informação tem, nos centros da América Latina, uma condição acadêmica especial, normativa e genérica, cuja aplicação em qualquer empresa formativa poucas vezes é posta em questão.

Assim, a problemática é mais evidente quando a relação entre teoria e prática é percebida sob a falsa crença de que toda formação significa, sem dúvida, dominar uma teoria como um conhecimento sistemático e instrumental. Não é considerada a possibilidade de uma orientação reflexiva sobre a prática, que ofereça subsídios para o estabelecimento de outros argumentos e que permita ou favoreça as condições para o docente acudir à teoria para enriquecer essa prática, segundo mostramos na FIG. 4. 


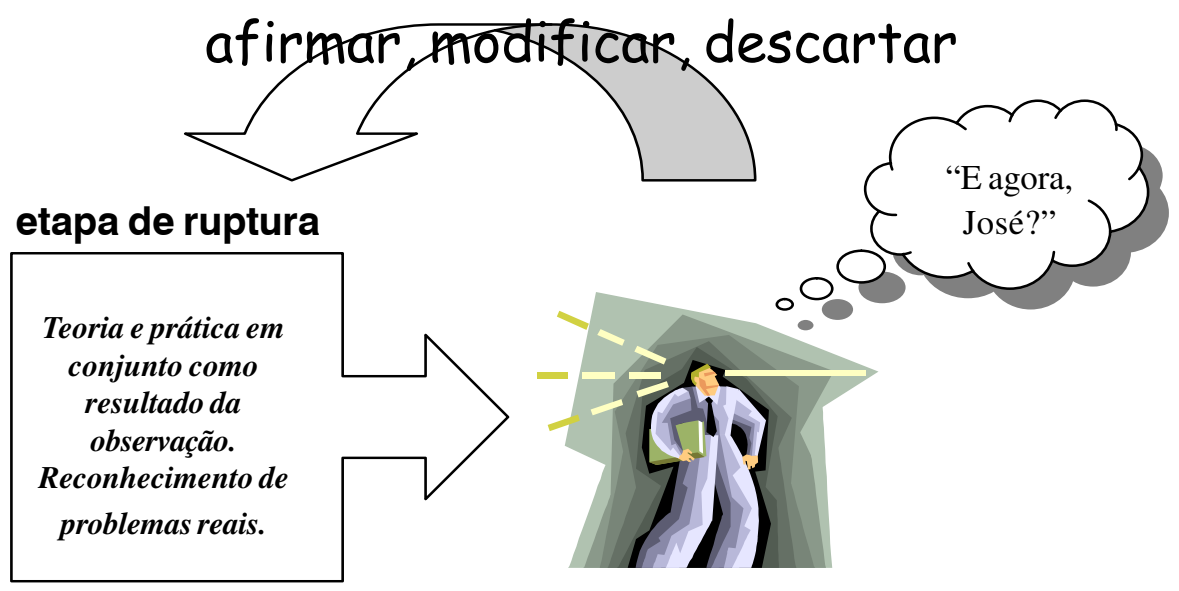

FIGURA 4 - A prática do docente de línguas e ele próprio como sujeito da sua pesquisa

O paradoxo no centro da discussão estaria então na presença, entre formadores e professores em formação, de duas visões diferentes sobre o que é a formação e o exercício profissional: uma de corte positivista (e até agora paradigmática), e outra crítica, a qual fundamenta sua existência na prática: "a competência profissional como a aplicacação do conbecimento privilegiado aos problemas" e [...] "a reflexão sobre a ação ("pensar no que se faz enquanto se faz') que algumas vezes os profissionais utilizam em situações de incerteza, singularidade e conflito" (SCHÖN, 1992, p. 9). Quer dizer, a visão da formação profissional como a aplicação de um conhecimento acabado ou a formação que inclua uma prática reflexiva perante os problemas colocados pela prática.

Nessa última perspectiva, Vez (2000, p. 195) destaca a existência atual de uma perda de confiança em uma sólida formação lingüística e, em alguns casos, o fato de se pensar que a melhor teoria é uma boa prática. E acrescenta que é importante observar como novos significados foram gerados para a relação teoria-prática, segundo destaca E. Ángel (1961, p. 131 apud STERN, 1983, p. 32):

Uma boa teoria sobre o ensino de línguas tentará oferecer um quadro conceitual que procure identificar todos os aspectos relevantes para o ensino de línguas e as relações entre eles, além de oferecer uma adequada 
direção para a prática do ensino de línguas, apoiada por uma pesquisa e consulta necessárias. ${ }^{15}$

Esses novos significados devem-se, em grande parte, ao papel de mediação da lingüística aplicada. Segundo Vez (1984, 2000, p. 200), nos últimos 50 anos, ela constituiu-se em um âmbito disciplinar de mediação, intervenção e resolução de problemas, até se perguntar de maneira crítica, menos teórica e convencional, acerca das conexões entre discurso, os usos lingüísticos e os contextos políticos e sociais em que se inscrevem as aprendizagens de línguas estrangeiras. É nesse contexto que podemos situar o professor de línguas (Ibid., p. 209):

Os docentes de línguas estrangeiras continuam construindo um conhecimento profissional fragmentado, segundo a sua capacidade de inovação tende a situar-se, quer à beira da orientação lingüística da abordagem comunicativa, quer à beira da sua orientação psicopedagógica e humanística. A linguagem - em qualquer de suas manifestações lingüísticas - chega a ser um elemento privilegiado de comunicação social, pelo seu carácter representativo, pela sua capacidade para representar a realidade de maneira compartilhada, o que nos faz compreender o processo de ensino-aprendizagem lingüística como um trabalho de construção e negociação de significados. ${ }^{16}$

\section{A formação teórico-crítica do docente}

Resumindo, podemos lembrar que algumas tradições de ensino de línguas estrangeiras destacam que o período formativo do docente começa

\footnotetext{
15 "A good language teaching theory will strive to provide a conceptual framework devised for identifying all factors relevant in the teaching of languages and the relationships between them and for giving effective direction to the practice of language teaching, supported by the necessary research and enquiry" (versão original; tradução nossa).

${ }^{16}$ Los docentes de lenguas extranjeras siguen construyendo un conocimiento profesional fragmentado en la medida en que su capacidad de innovación tiende a situarse, bien a la orilla de la orientación lingüística del enfoque comunicativo, o bien en la orilla de su orientación psicopedagógica y humanística. El lenguaje - en cualquiera de sus manifestaciones lingüísticas - llega a ser un elemento privilegiado de comunicación social gracias a su carácter representativo, a su capacidad para representar la realidad de una manera compartida, lo que nos lleva a comprender el proceso de enseñanzaaprendizaje lingüístico como una tarea de construcción y negociación de significados (tradução nossa)
} 
no momento em que o profissional decide integrar-se à atividade, e o final do mesmo período pode ser determinado quando as instituições certificam a sua habilitação como adequada, segundo a cobertura dos respectivos planos de estudo: domínio da língua, desempenho metodológico, reconhecimento de problemas inerentes à situação de ensino, conhecimento pertinente de trabalhos especializados, meios de avaliação, etc.

No entanto, o processo formativo real do professor persiste ao longo da sua experiência laboral, na qual afirma, modifica ou descarta os conhecimentos de que originalmente estava munido. A experiência de trabalho mantém em movimento constante grande parte da informação recebida e afirma ou favorece o estabelecimento de algumas crenças que regerão o desempenho cotidiano do professor. Tal como mostramos na primeira parte deste trabalho, se interrogado sobre as opções com que conta para estar atualizado, o profissional costuma reconhecer, de maneira geral e em primeiro lugar, as oportunidades que lhe oferecem os foros especializados, aos quais acode a procura de informação que lhe permita manter ativos os conhecimentos oferecidos pelo trabalho cotidiano.

Não faríamos objeção alguma sobre as oportunidades que esses espaços representam se não fosse porque regularmente a informação recebida é vista pelo sujeito como um meio para adquirir técnicas oferecidas como infalíveis ou que garantem efetividade, mas que podem estar desvinculadas ou serem alheias à problemática que o próprio trabalho pode oferecer.

De outra perspectiva, podemos afirmar que a realidade da sala de aula oferece ações e fenômenos suficientemente ricos para serem observados e problematizados, constituindo, ao mesmo tempo, uma oportunidade para o docente iniciar um trabalho diferente no seu desenvolvimento profissional.

\section{A díade docente-pesquisador}

Na consideração de um vínculo cada vez mais firme entre a pesquisa em lingüística aplicada e a realidade da sala de aula, é evidente que a formação continuada do profissional do ensino de línguas requer uma participação mais estreita entre docente e pesquisadores. Se pensarmos nas figuras do professor em formação e do professor em serviço, vemos na FIG. 5 como ambas são dinâmicas: 


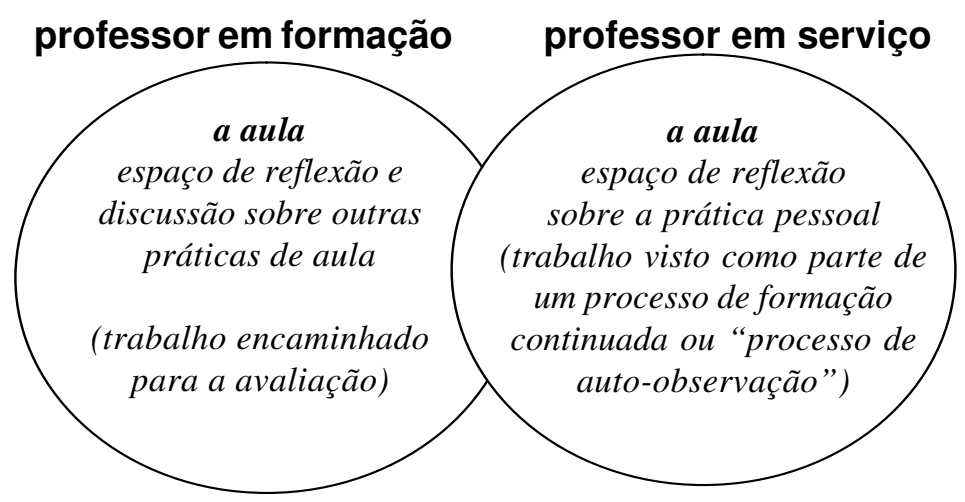

FIGURA 5 - Estudo da interação na sala de aula com implicações para a formação do professor

Fonte: A partir de uma idéia de Cavalcanti e Moita Lopes, 1991.

Observamos na FIG. 5 que, para ambas figuras, o professor em formação e o professor em serviço, o centro da atenção é o desempenho do profissional em um contexto específico: a aula e todos os pressupostos implicados na prática. O desejável seria que ambos pensassem na sua formação não só como uma instrumentação pedagógica ou metodológica de evolução conceitual (DÍAZ BARRIGA, 1990, p. 15) mas como uma formação para a pesquisa; que vissem sua matéria de estudo em correlação direta com o estabelecimento de uma cultura social igualmente crítica e móvel, porque o seu campo profissional faz parte das ciências sociais. Assim, a aula pode ser vista como um espaço para a tomada de decisões em condições de incerteza, na qual são negociados sentidos e produzemse significados, isto é, gera-se conhecimento.

\section{A integração da experiência cotidiana na pesquisa-ação}

Pensamos que é preciso fomentar no professor uma visão crítica da sua prática profissional. Essa visão crítica deve procurar a reflexão e a superação dos problemas concorrentes na prática docente. Essa prática docente constitui um espaço de reflexão e de cultura pedagógica de uma importância considerável que nem sempre foi levada em conta no planejamento educativo, em prol do simplesmente novo a que já nos referimos.

No processo de formação continuada do docente, e sob a guia dos pressupostos da pesquisa em sala de aula que veremos mais em frente, o 
desejável é a participação próxima e direta do professor em pesquisas e grupos de estudo interdisciplinar. A pesquisa-ação, por exemplo, oferece ao professor uma voz para fazer parte ativa na observação, a reflexão e a tomada de decisões; orienta-o para a implementação de mudanças ou ações organizadas, depois da identificação de um problema ou particularidade no seu trabalho acadêmico. Essas mudanças, conseqüência da observação detalhada dos fenômenos da sala de aula, procuram melhorar as características do trabalho de professores e alunos.

Em contraste com a pesquisa tradicional ou positivista, na qual os pesquisadores contam antecipadamente com hipóteses que conduzirão o estudo, na pesquisa-ação são fundamentais as apreciações do docente, na maneira em que se procede a problematizar ou fazer perguntas que orientarão as observações subseqüentes na pesquisa. Os resultados da pesquisa são dirigidos para ele próprio. É ele um dos principais interessados, por conhecer o que acontece na sua prática profissional.

A pesquisa-ação tem como parte das suas finalidades resgatar a voz do professor e situá-lo em uma perspectiva crítica e reflexiva sobre o seu trabalho na sala de aula, levando-o também a permanecer como um sujeito ativo no processo da sua formação continuada, tanto na ordem teórica quanto prática.

Dentro dessa prática, as tarefas mais relevantes são a observação da realidade da sala de aula, a determinação dos problemas por investigar, $a$ reflexão do docente sobre o próprio desempenho na aula, a procura de informação e o trabalho colaborativo entre pesquisadores e professores.

\section{A experiência do PIA-PLE}

O projeto "Interacción en el salón de clase de Portugués como Lengua Extranjera, Investigación-Acción (PIA-PLE)", realizado entre 1994 e 1998, teve como objetivo o estudo dos processos de aquisição do português como língua estrangeira em uma situação de aprendizagem formal, bem como o estudo dos problemas inerentes ao trabalho dentro da sala de aula; específicamente a observação das características do discurso dos participantes (alunos e professores), o discurso e a gramática, a interação e os processos de avaliação. Determinou-se que o projeto se realizasse na orientação e nas particularidades da pesquisa-ação, que detectasse problemas relativos à interação nesses três domínios, que propusesse ações para resolver tais problemas, que implementasse essas ações, que refletisse sobre os resultados da 
implementação das ações e que registrasse e divulgasse os resultados.

O projeto esteve integrado por Helena Maria da Silva Gomes Castro, como coordenadora, María Noemí Alfaro Mejía, Marisela Colín Rodea, Leonardo Herrera González e, em um primeiro momento, Dinorah Scott Lessa de Paula e José María Díaz de León.

Entre as características do trabalho de equipe - necessário para desenvolver um projeto dessa natureza - cabe salientar o caráter formativo do projeto para cada um dos participantes, quer na qualidade de pesquisadores, quer como participantes-professores. O trabalho específico da professora Helena da Silva era o de organizar, coordenar e dirigir as discussões no Seminário Central (também de caráter formativo) e as Sessões de Reconhecimento, em que se analisavam gravações de vídeo e se levantavam questões, a instância dos professores, que mereciam o acompanhamento na sala de aula, por meio de observações de prática docente. As ações implementadas na prática de aula dos nossos informantes tiveram também um impacto importante no trabalho do Departamento de Português do Centro, entre os professores participantes e entre os grupos em que a atividade foi realizada, especificamente entre os alunos que voluntariamente envolveram-se de maneira mais direta na pesquisa.

De maneira geral, podemos dizer que os resultados do projeto foram altamente produtivos em termos de formação docente, de pesquisa, de divulgação dos avanços e resultados em foros acadêmicos e em publicações. Constituiu-se um banco de dados muito valioso para a área do estudo de português como língua estrangeira (PLE). Permitiu também a realização de uma dissertação de mestrado e o início de uma outra de doutorado. Participamos em eventos acadêmicos nacionais e internacionais com vinte e cinco palestras e comunicações, e foram publicados oito artigos em revistas de prestígio; um exemplo é a antologia Contribuciones a la Lingüística Aplicada en América Latina. ${ }^{17}$ No entanto, provavelmente o maior valor da pesquisa esteja no fato de ela ter oferecido algumas respostas e novas perguntas, relevantes para a formação docente e para contribuir ao entendimento dos processos do ensino de PLE. Responderam-se

17 "Interacción y adquisición de la lengua extranjera: testimonio del discurso del salón de clase". In: Contribuciones a la Lingüística Aplicada en América Latina, Departamento de Lingüística Aplicada del CELE-UNAM, UNAM México, ISBN 968369843-3, p. 173-194. Primera impresión, feb. 2002. 
perguntas importantes relacionadas com a interação professor-aluno; com as características do discurso em termos de poder e de solidariedade; o discurso do professor como um input ótimo para a aquisição de uma L2; sobre a construção da competência comunicativa; sobre o ensino da gramática; sobre a avaliação e o tratamento do erro; sobre o papel da construção da linguagem verbal de maneira colaborativa na aprendizagem; e, finalmente, definiu-se e problematizou-se o modelo e as características da metodologia de pesquisa-ação para o contexto específico do nosso estudo, dado que se trata de uma metodologia com uma presença maior no campo da educação.

Podemos assinalar algumas questões levantadas a partir da nossa experiência no projeto PIA-PLE que mereceram nossa observação e problematização para serem transformadas em objeto de reflexão e de pesquisa:

- a imagem que o formador tem sobre os seus alunos-professores;

- os conceitos que os alunos-professores têm sobre o que é aprender e ensinar uma língua;

- as concepções de alunos e docentes em exercício profissional sobre a natureza da linguagem;

- a maneira que o docente propõe as atividades por realizar na sala de aula;

- a maneira que o docente dá instruções para os alunos;

- a maneira que o docente aborda ou explica aspectos gramaticais;

- os recursos discursivos ou metalingüísticos de que o professor dispõe;

- a maneira que os alunos se preparam para trabalhar na hora de chegar à sala de aula;

- o momento e a maneira mediante os quais a aula desvia-se do previsto;

- as repercussões do desvio na interação e na aprendizagem dos sujeitos presentes na sala de aula;

- o estabelecimento de um sistema de crenças e prefigurações;

- a reflexão a partir da observação da própria prática docente.

Esses foram alguns aspectos que puderam ser observados no trabalho docente e na interação na sala de aula. Os elementos não constituem um listado extensivo ou um roteiro, trata-se simplesmente de assuntos de reflexão que fizeram parte do interesse dos nossos informantes.

Mais uma vez, desejamos salientar a necessidade de promovermos as condições para que o docente de línguas possa investir tempo na sua formação ou profissionalização. 


\section{Comentário final}

Concluimos então que nos últimos anos a formação continuada teve como objetivo estabelecer um paralelismo entre a política institucional e as necessidades individuais da prática docente. Falou-se muito das transformações - ou da falta de transformações - efetuadas pelos cursos de formação de professores nos anos oitenta. Reconheceu-se também a problemática que representa planejar esses cursos e adequá-los, ao mesmo tempo, às políticas educativas de melhoramento e eficiência do ensino, visões em propagação na época. No entanto, sabemos que os interesses institucionais planejam programas globais que terminam fazendo ênfase nas ações de passar ou trocar informação e treinar o professor em determinada habilidade. A maioria desses programas termina sendo um fracasso, visto que a informação resulta alheia ao trabalho cotidiano do professor.

Porém, fica claro que, nos últimos anos, as pesquisas não consideram só o manejo do input na sala de aula, mas incluem outros fatores igualmente importantes, tais como: o modo em que opera a comunicação e se dá a cognição nesse espaço de intercâmbios sociais, a procura de condições mais favoráveis para o ensino e para a aprendizagem das línguas na sala de aula, as atividades e os seus sujeitos como principal fonte de informação. É nisso que consiste a atividade discursiva e cognitiva focalizada atualmente nesse espaço.

Assim, pensamos que a conclusão central, que se deriva da reflexão apresentada neste artigo, está relacionada com a formação teórico-crítica do professor, específicamente no valor da natureza mesma da pesquisaação, quer dizer, o fato de que este tipo de metodologia veja a relação entre a teoria e a prática como uma relação dialética, na qual a teoria e a prática do pesquisador e do professor convergem ao transformarem-se ambas em praxes específicas, em ações refletidas e comprometidas. Por isso, a meta da pesquisa-ação é a reflexão auto-crítica, compartilhada por todos os atores do ato de pensar sobre a prática escolar (professores, alunos, pesquisadores), reflexão que ajuda os "praticantes" a emancipar-se dos hábitos impostos, dos costumes e das estruturas sociais coercitivas.

Finalmente, devemos lembrar que o elemento personalizado, isto é, a nossa experiência como sujeitos participantes no projeto PIA-PLE, implica uma reflexão constante que acompanha a prática docente e de pesquisa, que na voz do professor se traduz em um enunciado do tipo: - "Não posso deixar de pensar no que faço". Dessa maneira, a proposta da pesquisa-ação constitui uma orientação metodológica que permite estabelecer a convergência entre a pesquisa, a prática docente e a formação de professores. 


\section{Referencias Bibliográficas}

ALMEIDA FILHO, J. C. P. Dimensões comunicativas no ensino de línguas. Campinas, S. P.: Pontes, 1993.

CUENCA, M. J. Teories Gramaticals i ensenyament de llengues. Valencia: Tàndem Edicions, 1998.

DÍAZ BARRIGA, A. Investigación educativa y formación de profesores. Contradicciones de un articulación. Cuadernos del CESU, n. 20, Coordinación de Humanidades, Centro de Estudios sobre la Universidad, UNAM, México, 1990.

GERMAIN, C. El enfoque comunicativo: qué y cómo enseñar. III ENCUENTRO NACIONAL DE PROFESORES DE LENGUAS, CELE-UNAM, México, 1984. Mímeo.

MOITA LOPES, L. P. Oficina de Lingüística Aplicada: a natureza social e educacional dos processos de ensino/aprendizagem de línguas. Campinas, S.P.: Editora Mercado de Letras, 1996. (Col. Letramento, Educação e Sociedade)

MOITA LOPES, L. P. A nova ordem mundial, os parâmetros curriculares nacionais e o ensino de inglês no Brasil: a base intelectual para uma ação política. In: BÁRBARA, Leila; RAMOS, Rosinda de Castro Guerra (Org.). Reflexos e ações no ensino-aprendizagem de Linguas. Campinas, S. P.: Editora Mercado de Letras, 2003. (Col. As faces da Lingüística Aplicada)

RICHARDS; NUNAN. Second Language Teacher Education. Cambridge: Cambridge University Press, 1990.

SCHÖN, D. A. La formación de profesionales reflexivos: hacia un nuevo diseño de la enseñanza y el aprendizaje en las profesiones. Barcelona: Temas de Educación Paidós, Ministerio de Educación y Ciencia, 1992.

SEEDHOUSE, P. Linking pedagogical purposes to linguistic patterns of interaction: the analisis of communication in the language classroom. IRAL, XXXII, n. 4, p. 303-320, 1994.

STERN, H. H. Fundamental concepts of language teaching. London: Oxford University Press, 1983.

VEZ, J. M. Fundamentos lingüísticos en la enseñanza de letras extranjeras. Barcelona: Editorial Ariel, 2000.

WILLIAMS, M. A developmental view of classroom observations. ELT Journal, v. 3, 2 abr. 1989. 